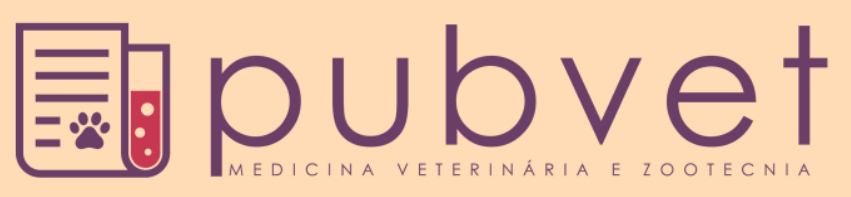

https://doi.org/10.22256/pubvet.v12n2a31.1-6

\title{
Isolamento e identificação de Tricophyton mentagrophytes como causador de otite fúngica em gato: Relato de Caso
}

\author{
Mariane Vieira de Sá ${ }^{\oplus}{ }^{*}$, Joisiane da Silva $\operatorname{Santos}^{\ominus}$, Savio Matheus Reis de Carvalho ${ }^{\bullet}$, Eva \\ lopes $^{1}$, Lygia Silva Galeno ${ }^{\ominus}$, Jenilton da Silva Nunes ${ }^{\ominus}{ }^{3}$, Maria Santos Oliveira ${ }^{\ominus}{ }^{4}$, Feliciana \\ Clara Fonsêca Machado 5 , Antonio Augusto Nascimento Machado Júnior 5

\begin{abstract}
'Discente do curso de Medicina Veterinária, Universidade Federal do Piauí. Campus Professora Cinobelina Elvas, Bom Jesus, Piauí, Brasil. E-mail: marivieira15@hotmail.com, silvajoisiane@gmail.com, savioreis1995@gmail.com, evalopes53@hotmail.com ${ }^{2}$ Discente em Universidade Estadual do Maranhão, Campus Paulo VI. São Luís-MA. Brasil. E-mail: lygiagaleno@outlook.com ${ }^{3}$ Agente de Endemias, Secretaria de Saúde, Prefeitura Municipal de Bom Jesus, Piauí, Brasil. E-mail: jenilton18@ hotmail.com ${ }^{4}$ Médica Veterinária, Pós-graduanda do Mestrado em Zootecnia, Universidade Federal do Piauí, Campus Professora Cinobelina ElvasCPCE, Bom Jesus, Piauí, Brasil.educacaomaria@hotmail.com

${ }^{5}$ Professor (a) Doutor (a) do curso de Medicina Veterinária, Universidade Federal do Piauí, Campus Professora Cinobelina Elvas, Bom Jesus, Piauí, Brasil.E-mail: feliciannaclarafs@hotmail.com, machadojunior@gmail.com

*Autor para correspondência: e-mail: marivieira_15@hotmail.com
\end{abstract}

\begin{abstract}
RESUMO. Objetivou-se, neste trabalho, fazer o relato de um caso de otite fúngica em um gato atendido no Hospital Veterinário Universitário do Campus Professora Cinobelina Elvas da Universidade Federal do Piauí, em Bom Jesus-PI. O animal foi encontrado, abandonado na rua, mostrando sinais de necrose e destruição da cartilagem auricular e foi levado para atendimento. Tratava-se de um felino, fêmea, com aproximadamente dois anos de idade e com um quadro de lesões dermatológicas na cabeça. Realizou-se anamnese onde se verificou presença de miíase. No exame físico geral observou-se que o animal apresentava um estado físico geral ruim, com desidratação, emagrecimento, dermatite úmida com destruição da cartilagem auricular, bilateralmente, e uma área de necrose caudal à implantação da cartilagem auricular esquerda. Diante dos sinais suspeitou-se de neoplasia ou esporotricose. Foi coletado material para exames laboratoriais. A citologia aspirativa não revelou sinais de neoplasia. No raspado de pele ficou evidenciada a presença de fungos que na cultura revelou tratar-se de Trichophyton mentagrophytes. $\mathrm{O}$ tratamento inicial do animal, além da retirada das miíases, foi com antibioticoterapia com penicilina (24.000 $\mathrm{UI} / \mathrm{kg}$ ) e estreptomicina $(10 \mathrm{mg} / \mathrm{kg}) / \mathrm{q} 5 \mathrm{~d} / \mathrm{IM}$, limpeza e curativos diários. Após o resultado da cultura iniciou-se o tratamento com itraconazol $5 \mathrm{mg} / \mathrm{kg} / \mathrm{BID}$, via oral, porém o tratamento foi interrompido devido o animal ter fugido e não ter sido mais encontrado. Observa-se com isso, a importância dos meios complementares para diagnóstico desse tipo de patologia, bem como a importância de se identificar com brevidade o agente etiológico do processo, para com isso, evitar que animal sofra perda tecidual irreversível e passe por grandes desconfortos.
\end{abstract}

Palavras chave: Cultura fúngica, dermatofitose, micoses, tratamento

\section{Isolation and identification of Trichophyton mentagrophytes as a cause of fungal otitis in cats: Case Report}

ABSTRACT. The objective of this study was to report a case of fungal otitis in a cat treated at the University Veterinary Hospital Campus Professor Cinobelina Elvas of the Federal University of Piauí, Bom Jesus-PI. The animal was found, abandoned on the street, showing signs of necrosis and destruction of the auricular cartilage and was washed for care. It was a feline, females, about two years old with a picture of dermatological lesions 
on the head. Anamnesis was performed where myiasis was present. The general physical examination showed that the animal had a poor general physical condition, with dehydration, weight loss, wet dermatitis with destruction of the auricular cartilage bilaterally, and an area of caudal necrosis to the implantation of the left atrial cartilage. Before the signs were suspected of neoplasia or sporotrichosis. Material was collected for laboratory tests. Aspiration cytology showed no signs of neoplasia. In the scraping of the skin was evidenced the presence of fungi that in the culture revealed to be Trichophyton mentagrophytes. The initial treatment of the animal, in addition to the removal of the myiasis, was with antibiotic therapy with penicillin $(24,000 \mathrm{IU} / \mathrm{kg})$ and streptomycin $(10 \mathrm{mg} / \mathrm{kg}) / \mathrm{q} 5 \mathrm{~d} / \mathrm{IM}$, cleaning and daily dressings. After the culture was started treatment with itraconazole $5 \mathrm{mg} / \mathrm{kg} / \mathrm{BID}$ was orally administered, but the treatment was interrupted because the animal had escaped and was no longer found. Thus, the importance of complementary means for diagnosis of this type of pathology, as well as the importance of identifying the etiological agent of the process, in order to prevent the animal from suffering irreversible tissue loss and passing through great discomforts is observed.

Keywords: Fungal culture, dermatophytosis, mycoses, treatment

\section{Aislamiento e identificación de Trichophyton mentagrophytes como causante de otitis fúngica en gato: Reporte de un caso}

RESUMO. En este trabajo, se objetivó, relatar un caso de otitis fúngica en un gato atendido en el Hospital Veterinario Universitario del Campus Profesora Cinobelina Elvas de la Universidade Federal de Piauí, en Bom Jesús-PI. El animal fue encontrado, abandonado en la calle, mostrando signos de necrosis y destrucción del cartílago auricular y fue llevado para atendimiento clínico. Se trataba de una hembra felina, con aproximadamente dos años de edad y con un cuadro de lesiones dermatológicas en la cabeza. Se realizó anamnesis donde se verificó presencia de miasis. En el examen físico se observó que el animal presentaba un estado físico general reservado, con deshidratación, desnutrición, dermatitis húmeda con destrucción del cartílago auricular bilateralmente, y un área de necrosis caudal a la implantación del cartílago auricular izquierdo. Ante las señales se sospechó de neoplasia o esporotricosis. Se recogió material para exámenes de laboratorio. La citología aspirativa no reveló signos de neoplasia. En el raspado de piel quedó evidenciada la presencia de hongos que en la cultura reveló tratarse de Trichophyton mentagrophytes. El tratamiento inicial del animal, además de la retirada de las miasis, fue con antibioticoterapia con penicilina $(24.000 \mathrm{UI} / \mathrm{kg})$ y estreptomicina $(10 \mathrm{mg} / \mathrm{kg}) / \mathrm{q} 5 \mathrm{~d} / \mathrm{IM}$, limpieza y curativos diarios. Después del resultado de la cultura se inició el tratamiento con itraconazol 5 $\mathrm{mg} / \mathrm{kg} / \mathrm{BID}$, vía oral, pero el tratamiento fue interrumpido debido a que el animal huyó y no se encontró más. Se observa con ello la importancia de los medios complementarios para el diagnóstico de este tipo de patología, así como la importancia de identificarse con brevedad el agente etiológico del proceso, y con ello, evitar que el animal sufra pérdida del tejido irreversible y pase por desconforto.

Palabras chaves: Cultivo fúngico, dermatofinesis, micosis, tratamiento

\section{Introdução}

As dermatofitoses são as micoses mais frequentes em felinos e podem ser causadas por fungos de três gêneros distintos: Trichophyton spp, Epidermophyton spp e Microsporum spp. Trata-se de uma antropozoonose, com importância na saúde pública (Eichenberg et al., 2003). Os fungos dermatófitos são caracterizados pela elevada afinidade por substratos queratinizados presentes na pele, pelos, cabelos, unhas, cascos, chifres e bicos (Avante et al., 2009). Algumas vezes, especialmente na fase crônica da doença, esses fungos podem desencadear micoses subcutâneas denominadas de pseudomicetomas dermatofíticos (Tostes \& Giuffrida, 2003).

Trichophyton mentagrophytes é um fungo zoofílico e patogênico que pode ser isolado em coelhos, roedores, cães e gatos, tendo grande afinidade por felinos domésticos. Entretanto, é também um dos dermatófitos menos descritos na 
literatura (Schoeler et al., 2010). Bernardo et al. (2005), em um levantamento de fungos dermatófitos isolados, evidenciaram a presença Trichophyton mentagrophytes em 7,9\% dos gatos. As lesões características de dermatofitose causada por T. mentagrophytes são alopecia, eritema, descamação, crostas e envolvendo a cabeça e extremidades (Outerbridge, 2006). A identificação dessa espécie de fungo de forma rápida é importante para iniciar um tratamento precoce possibilitando que o prognóstico seja mais favorável.

O diagnóstico pode ser feito com base em exames laboratoriais ou por meio da lâmpada de Wood, sendo que nesta modalidade a não observação de fluorescência não descarta a presença de fungo. Os exames laboratoriais incluem microscopia direta dos pelos arrancados dos animais, histopatológico observando-se os elementos fúngicos em cortes histopatológicos e a cultura fúngica (Outerbridge, 2006).

O objetivo do presente trabalho foi fazer o relato de um caso de otite fúngica causada por Trichophyton mentagrophytes em um gato.

\section{Relato de Caso}

Foi atendido no Hospital Veterinário Universitário, localizado na Universidade Federal do Piauí, Campus Professora Cinobelina Elvas na Cidade de Bom Jesus- PI, um gato, fêmea, sem padrão de raça definida, de aproximadamente dois anos de idade, pesando $1,70 \mathrm{~kg}$, com pelagem branca.

Durante anamnese o proprietário relatou que o animal foi encontrado na rua sem histórico prévio, caquético e respiração ofegante, com alto grau de desidratação, lesões ulcerativas profundas com áreas necrosadas na cabeça, presença de miíase e secreção mucosanguinolenta. $\mathrm{O}$ mesmo se encontrava com destruição de ambas as cartilagens auriculares (Figura 1). No mesmo dia que foi encontrada foram retiradas as miíases e em seguida foi feita higiene corporal com banho e limpeza das lesões com solução fisiológica e detergente neutro e foi feito bandagem na cabeça do animal para evitar novas recidivas de miíase. $\mathrm{O}$ proprietário fez administração oral de complexo vitamínico para estimular o apetite e o sistema imunológico do animal. Desde então o animal passou a se alimentar de ração, comida caseira e sachet de carne três vezes ao dia. A gata passou a viver na área de serviço da casa do tutor, com acesso livre para realização de micção e defecação, ambas relatadas com aspecto normal, segundo o tutor.

Durante exame clinico geral o animal apresentava comportamento dócil, escore corporal caquético e com grau de desidratação $8 \%$, mucosas pálidas, linfonodos submandibular, préescapular e poplíteo aumentados, tempo de preenchimento capilar (TPC) $>2 \mathrm{~s}$, temperatura retal (TR) $39,5^{\circ} \mathrm{C}$, frequência respiratória (FR) 18 mov./min e Frequência cardíaca (FC) 120 bat./min. Na ausculta pulmonar observou- se som de estertor úmido na região caudal do pulmão direito e esquerdo. Nos achados físicos foi observado prurido intenso na região da orelha externa, secreção escura com odor fétido, indicativo de otite externa. Eritema e presença dermatite úmida nas patas torácicas, olho esquerdo e direito apresentavam secreção aquosa e escoriações leves na pálpebra inferior esquerda e direita. Nos sistemas geniturinários, digestório, locomotor e nervoso não foram observadas alterações.

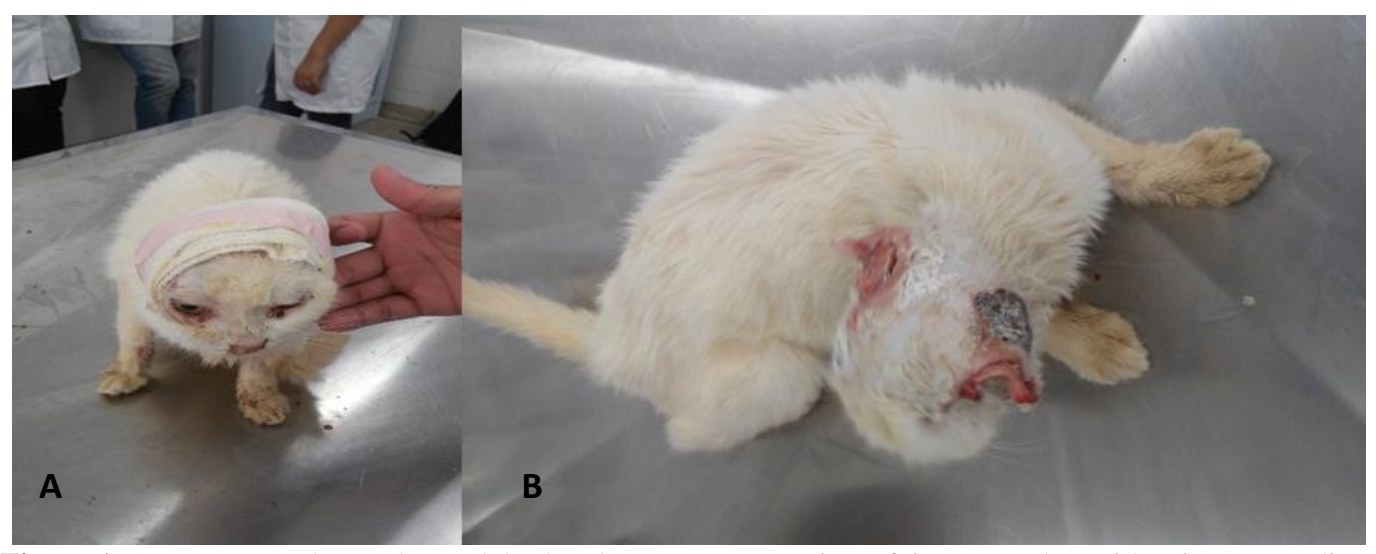

Figura 1. Apresentação do estado geral de abandono em que o paciente foi encontrado. Evidencia-se a condição geral do animal quando da chegada no Hospital Veterinário (A). Observa-se a condição de subnutrição, pelos eriçados e sem brilho, perda das cartilagens auriculares direita e esquerda e presença de região de necrose caudal a base da orelha esquerda (B). 
Inicialmente foi feito debridamento cirúrgico manual com o auxílio de gases e depois foi feita limpeza da lesão com soro fisiológico (Figura 2), seguido de antissepsia com clorexidine e aplicação de pomada tópica à base de gentamicina $0.5 \mathrm{~g}$, sulfanilamida $5,0 \mathrm{~g}$ e sulfadiazina $5,0 \mathrm{~g}$ e por último foi feito bandagem em toda a cabeça da gata. Para corrigir a desidratação foi feita aplicação intravenosa (IV) de soro glicosado, dois frascos de $100 \mathrm{ml}$ cada. Foi realizada antibioticoterapia com penicilina $(24.000 \mathrm{UI} / \mathrm{kg}) \mathrm{e}$ estreptomicina $(10 \mathrm{mg} / \mathrm{kg}) / \mathrm{q} 5 \mathrm{~d} / \mathrm{IM} \quad \mathrm{e}$ antiinflamatório com meloxican $0,1 \mathrm{mg} / \mathrm{kg} / \mathrm{BID}$ durante cinco dias. Recomendou-se a limpeza duas vezes ao dia das lesões e utilização da pomada tópica associada com açúcar e cobrir a ferida para evitar reinfestação de miíase.

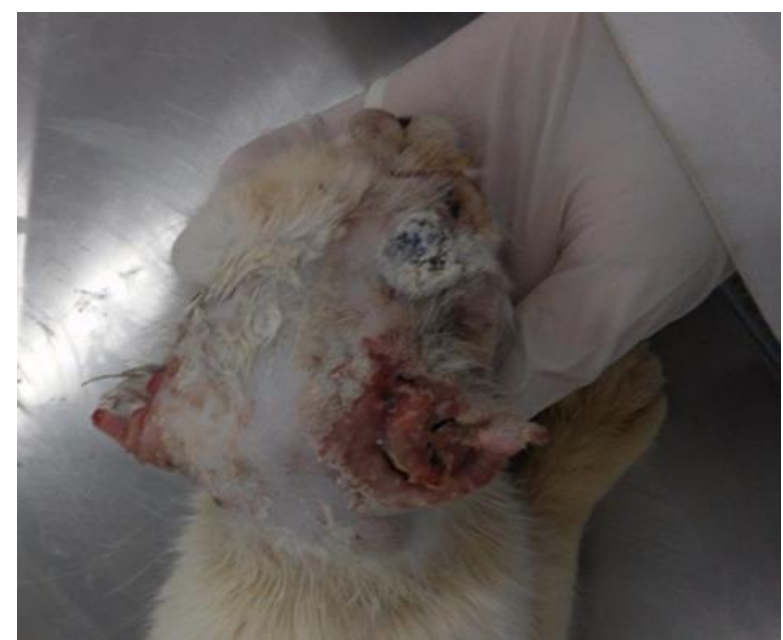

Figura 2. Aspecto geral do animal mostrando a ferida antes da limpeza e evidenciando-se o caráter destrutivo da doença e a condição inicial do paciente antes de iniciar os procedimentos terapêuticos.

Diante da característica das lesões apresentadas, suspeitou-se inicialmente que o animal poderia ter um quadro de neoplasia ou esporotricose, haja vista o caráter destrutivo das lesões.

Foi realizado um hemograma para avaliação dos parâmetros hematológicos, citologia otológica para avaliação microscópica e cultura, raspado de pele e punção aspirativa com agulha fina (PAAF). Os exames complementares apresentaram os seguintes resultados: no swab otológico do ouvido esquerdo foi negativo para ácaros, porém positivo para o fungo Malassezia sp, bactérias dos tipos coccus $(70 \%)$ e bastão (30\%) e presença de células polimorfos nucleares. No ouvido direito o swab foi negativo para ácaros e Malassezia sp, mas se mostrou positivo para bactérias tipo coccus $(50 \%)$ e tipo bastão (50\%) e células polimorfos nucleares e hemácias. No hemograma o animal apresentou anemia com de hematócrito $16,5 \%$ e eritrócitos de $3.670 .000 / \mu \mathrm{L}$. Leucocitose por neutrofilia com desvio à esquerda, sendo indicativo de presença de neutrófilos jovens, anisocitose, e neutrófilos com granulações tóxicas. Na PAAF não foi observada células sugestivas de neoplasia. A cultura fúngica, do raspado de pele, indicou a presença do fungo dermatófito Tricophyton mentagrophytes.

Além do tratamento já descrito com antibioticoterapia, anti-inflamatório e terapia tópica, iniciou-se o tratamento com itraconazol 5 $\mathrm{mg} / \mathrm{kg} / \mathrm{BID} / \mathrm{VO}$, porém antes que se pudesse avaliar a eficácia terapêutica, o tratamento foi interrompido devido o animal ter fugido e não ter sido mais encontrado.

\section{Discussão}

Quando o clínico se depara com um quadro de dermatopatia, um dos passos mais importante para o sucesso terapêutico é o diagnóstico rápido e correto, pois sem a definição da verdadeira causa, pode-se incorrer em tratamentos ineficazes o que resultará em retardo ou agravamento do problema. Após encontrar-se a causa outra etapa importante é a definição de um plano terapêutico adequado, o qual deve levar em consideração a condições orgânica do paciente e o grau de compromisso do tutor em colaborar no tratamento de modo que este possibilite bons resultado a remissão dos sinais clínicos (Peixoto et al., 2002).

Para o caso em questão, no qual ficou evidenciada a presença do fungo dermatófito Tricophyton mentagrophytes, a literatura recomenda a utilização de fungicidas tais como a griseofulvina, cetoconazol ou itraconazol, via oral por um período de tempo variando de 60 a 90 dias, com avaliações posteriores para definição da cura clínica e suspensão do tratamento (Ramadinha et al., 2010).

No presente trabalho o tratamento de escolha foi o itraconazol devido ao seu baixo custo, por apresentar poucas reações adversas, além de possuir uma boa ação contra esse patógeno (Nobre et al., 2002). O itraconazol é um triazol semelhante aos derivados imidazólicos. Os microrganismos susceptíveis incluem os dermatófitos, cândidas, malassézias e aqueles que causam micoses profundas. Nas dermatofitoses está indicado na dose de 5 a $10 \mathrm{mg} / \mathrm{kg}$, a cada 12 ou 24 horas e é mais eficiente que o cetoconazol por apresentar menos reações adversas (Jaham et al., 2000). A 
griseofulvina é muito eficaz e segura na dose de $50 \mathrm{mg} / \mathrm{kg}$ a cada 24 horas e o cetoconazol tem boa eficácia na dose de $5 \mathrm{mg} / \mathrm{kg}$ a cada 24 horas, mas ambos acarretam efeitos colaterais como inapetência, êmese e alterações hepáticas com maior frequência quando comparados com o itraconazol (Balda et al., 2004).

Ben-Ziony \& Arzi (2000) relataram à eficácia de lufenuron em dose única de 51,2 a $266 \mathrm{mg} / \mathrm{kg}$ e os felinos foram considerados clinicamente curados 10 a 15 dias após o tratamento para dermatofitose. Gatos tratados com terbinafina ficaram curados em 8,6 semanas, os que receberam o lufenuron apresentaram cura em 9,3 semanas e os animais medicados com ambas as drogas necessitaram de 8,7 semanas para a cura.

O animal deu entrada na clínica com lesões na cabeça. Segundo Balda et al. (2004) a localização das lesões por dermatófitos em felinos são observadas preferencialmente na cabeça e nos membros.

No presente relato o açúcar foi utilizado como auxilio no tratamento das lesões inicialmente observadas devido sua ação cicatrizante e bactericida. Esta informação encontra-se amparada no relato de Lima et al. (2015) quando afirmaram que o açúcar cristal é um excelente produto bactericida e bacteriostático, capaz de acelerar a cicatrização, diminuindo o índice de contaminação bacteriana, ajudando na formação do tecido de granulação, além de ser um produto de baixo custo.

Nos exames complementares, o paciente apresentou Malassezia sp na orelha, sendo esta uma levedura oportunista, já que é comumente encontrada como microbiota natural do conduto autidivo. Eichenberg et al. (2003) relataram que esta levedura, é considerada normal na pele, mas que pode ser patogênica e oportunista do conduto auditivo externo de cães e gatos, podendo o prognóstico ser bom quando a causa primaria é identificada e corrigida.

\section{Conclusão}

Conclui-se, com base nas observações feitas, que são de grande importância os meios complementares para diagnóstico das dermatofitoses, haja vista as lesões serem muito parecidas com as observadas em outros problemas, que são considerados quando do diagnóstico diferencial, tais como neoplasia, ácaros e outros fungos. Outro aspecto é com relação a importância de se identificar com brevidade o agente etiológico do processo, para com isso, evitar que animal sofra perda tecidual irreversível e passe por grandes desconfortos, pois a infecção fúngica certamente proporcionou lesões que facilitaram a infestação por miíase, a qual foi responsável pela maior parte do dano tecidual observado no animal.

\section{Referências Bibliográficas}

Avante, M. L., Campos, C. P., Ferreira, M. M. G., Martins, I. S., Rosa, B. R. T., Sousa, G. D. P. \& Avanza, M. F. B. 2009. Dermatófitose em grandes animais. Revista Cientifica Eletrônica de Medicina Veterinaria, 12.

Balda, A. C., Larsson, C. E., Otsuka, M. \& Gambale, W. 2004. Estudo retrospectivo de casuística das dermatofitoses em cães e gatos atendidos no Serviço de Dermatologia da Faculdade de Medicina Veterinária e Zootecnia da Universidade de São Paulo. Acta Scientiae Veterinariae, 32, 133-140.

Ben-Ziony, Y. \& Arzi, B. 2000. Use of lufenuron for treating fungal infections of dogs and cats: 297 cases (1997-1999). Journal of the American Veterinary Medical Association, 217, 1510-1513.

Bernardo, F., Lança, A., Guerra, M. M. \& Marina, M. H. 2005. Dermatófitos isolados de animais de companhia (cão e gato), em Lisboa, Portugal (2000-2004). Revista Portuguesa de Ciencias Veterinária, 100, 85-88.

Eichenberg, M. L., Appelt, C. E., Berg, V., Muschner, A. C., Nobre, M. d. O., Matta, D., Alves, S. H. \& Ferreiro, L. 2003. Susceptibility of Malassezia pachydermatis to azole antifungal agents evaluated by a new broth microdilution method. Acta Scientiae Veterinariae, 31, 75-80.

Jaham, C., Paradis, M. \& Papich, M. G. 2000. Antifungal dermatologic agents: azoles and allylamines. Compendium on Continuing Education for the Practicing Veterinarian, 22, 548-559.

Lima, D. C. M., Gonçalves, R. C., Tanaka, N. M. \& Silva, L. C. S. 2015. Açúcar cristal no processo cicatricial de ferida contaminada em ovino. Journal of Health Sciences, 14, 175184.

Nobre, M. O., Silva, P. N., Meireles, M. C. \& Ferreiro, L. 2002. Drogas antifúngicas para pequenos e grandes animais. Ciência Rural, 32, 175-184. 
Outerbridge, C. A. 2006. Mycologic disorders of the skin. Clinical Techniques in Small Animal Practice, 21, 128-134.

Peixoto, A. S., Coelho, M. C. O. C. \& Barbosa, M. B. 2002. Atualidades em tratamentos utilizados em dermatopatias de cães-revisão. Revista de Educação Continuada em Medicina Veterinária e Zootecnia do CRMV-SP, 5, 1424.

Ramadinha, R. R., Reis, R. K., Campos, S. G., Ribeiro, S. S. \& Peixoto, P. V. 2010. Lufenuron no tratamento da dermatofitose em gatos? Pesquisa Veterinária Brasileira, 30, 132-138.

Schoeler, A., Cembranel, L., Sguissardi, C. H., Bernardi, E. \& Fuentefria, A. M. 2010.
Prevalência de dermatófitos na rotina de micologia em hospital particular de médio porte na cidade de Chapecó, estado de Santa Catarina, Brasil. Revista de Ciências Farmacêuticas Básica e Aplicada, 31, 103106.

Tostes, R. A. \& Giuffrida, R. 2003. Pseudomicetoma dermatofítico em felinos. Ciência Rural, 33, 363-365.

Article History:

Received 12 October 2017

Accepted 1 Nobember 2017

Available online 15 Jenuary 2017

License information: This is an open-access article distributed under the terms of the Creative Commons Attribution License 4.0, which permits unrestricted use, distribution, and reproduction in any medium, provided the original work is properly cited. 